\title{
Sistem Informasi Stok Gudang Koperasi Menggunakan Supply Chain Management
}

\author{
Arfiani Nur Khusna*, Fahmi Ardhi Nugraha

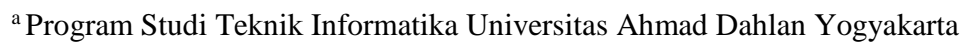

Naskah Diterima : 12 Oktober 2018; Diterima Publikasi : 21 November 2018

DOI : $10.21456 /$ vol8iss2pp203-210

\begin{abstract}
The cooperative is faced with the problem of how to keep the availability of goods in the warehouse sufficient, not experiencing upperstock or understock in the stock inventory system. The Supply Chain Management approach can help overcome the problem of availability of goods by integrating suppliers efficiently. The study aims to produce information about the stock of goods and the number of orders for the next period so that it can make a suitable budget plan. Collecting data is the first step and then designing the pattern of supply chain management flow, supply chain management strategies include the use of pareto $\mathrm{ABC}$ classification to give priority to supervision of inventory and determination of purchase points by calculating Economy Order Quantity (EOQ), process flow, implementation and testing. The system produces goods stock information that is able to provide accurate information about the remaining stock of goods in the warehouse along with calculation calculations for the purchase of each item at an economical price and amount, for the determination of product reorder time (Reorder Point), the average product lead time is 2 days, the usage rate per day for rice is 0.34 and the safety stock of rice is 20 sacks so that if the rice has reached the 3 point sack then the cooperative must re-order. The test results using usability test showed that $66.66 \%$ of the questions were able to be answered by the respondents and the test results between $65-84 \%$ were declared good so that the application was feasible and usable.
\end{abstract}

Keywords: Supply Chain Management; ABC Pareto; Economy Order Quantity.

\begin{abstract}
Abstrak
Koperasi dihadapkan pada masalah yaitu bagaimana menjaga ketersediaan barang di gudang tetap mencukupi, tidak mengalami upperstock ataupun understock dalam sistem pendataan stok barang. Pendekatan Supply chain management dapat membantu mengatasi masalah ketersediaan barang dengan mengintegrasikan supplier secara efisien. Penelitian bertujuan untuk menghasilkan informasi mengenai stok barang beserta jumlah pemesanan barang untuk periode selanjutnya sehingga dapat membuat rancangan anggaran yang sesuai. Pengumpulan data merupakan langkah awal kemudian melakukan perancangan pola aliran supply chain management, strategi mengelola supply chain management meliputi penggunaan klasifikasi $A B C$ pareto untuk memberikan prioritas pengawasan persediaan barang dan penentuan titik pembelian dengan perhitungan Economy Order Quantity (EOQ), alur proses, implementasi dan pengujian. Sistem menghasilkan informasi stok barang yang mampu memberikan informasi akurat mengenai sisa stok barang di gudang beserta kalkukasi perhitungan untuk pembelian masingmasing barang dengan harga dan jumlah yang ekonomis, untuk penentuan waktu pemesanan kembali produk (Reorder Point), rata-rata lead time produk adalah 2 hari, tingkat pemakaian per hari untuk beras adalah 0.34 dan safety stock beras adalah 20 karung sehingga apabila beras sudah mencapai titik 3 karung maka pihak koperasi harus melakukan pemesanan kembali. Hasil pengujian menggunakan usability test menunjukkan bahwa $66.66 \%$ pertanyaan mampu dijawab oleh responden dan nilai hasil pengujian antara $65-84 \%$ dinyatakan baik sehingga aplikasi layak dan dapat digunakan.
\end{abstract}

Kata kunci: Supply Chain Management; ABC Pareto; Economy Order Quantity.

\section{Pendahuluan}

Koperasi merupakan suatu perkumpulan yang beranggotakan orang-orang atau badan hukum koperasi yang memberikan kebebasan masuk dan keluar sebagai anggota, dengan bekerjasama secara kekeluargaan menjalankan usaha untuk mempertinggi kesejahteraan para anggotanya (Permadi, 2014).

*) Penulis korespondensi: arfiani.khusna@tif.uad.ac.id
Masalah yang dihadapi oleh koperasi yang terdapat pada suatu intansi salah satunya adalah bagaimana menjaga agar ketersediaan barang di gudang tetap mencukupi tidak mengalami upperstock ataupun understock dan sistem pendataan stok barang di gudang itu sendiri. Sistem persediaan barang biasanya terdiri dari sistem penerimaan barang, sistem pembelian barang dan sistem gudang. Semakin tinggi 
permintaan akan suatu barang maka koperasi harus menyediakan stok yang cukup untuk memenuhi permintaan tersebut. Terjaganya ketersediaan stok gudang yang baik akan menjadi dasar berjalannya proses bisnis di suatu koperasi atau bidang usaha manapun (Purwanto, 1994).

Supply chain management serangkaian pendekatan yang digunakan untuk mengintegrasikan supplier secara efisien, sehingga barang-barang dapat didistribusikan dengan jumlah yang tepat, ke lokasi yang tepat, dan waktu yang tepat juga, dengan maksud meminimalkan keseluruhan sistem (Indrajit, 2002).

Penggunaan supply chain management dalam perusahaan dengan adanya persaingan dan pertumbuhan teknologi yang cepat, senantiasa menuntut perusahaan untuk mengubah proses bisnis internal yang sedang berjalan. Hadirnya teknologi informasi yang perkembangannya berlangsung secara berkesinambungan pada dekade terakhir ini telah meningkatkan efektifitas dan efisiensi dari proses bisnis yang ada secara signifikan (Chopra, 2007). Namun demikian, seiring dengan perkembangan kebutuhan perusahaan yang terus-menerus dan kompleks, bisnis pun dituntut untuk mengadakan integrasi sistem antar perusahaan (Saputro, 2017)

Permasalahan di suatu koperasi yaitu pendataan stok barang digudang ke komputer kerja belum terformat dengan baik karena belum adanya sistem yang dapat mendukung pendataan, anggota koperasi mengalami kesulitan dalam mencari informasi sisa stok barang digudang dan juga barang yang datang dari pihak supplier tidak menentu dengan harga yang fluktuatif, anggota koperasi mengalami kerugian pada saat mendatangkan barang dari supplier karena anggaran yang diberikan untuk belanja tidak sesuai dengan harga yang diberikan oleh supplier, serta jumlah barang yang dikirimkan terkadang tidak sesuai dengan kebutuhan karena anggaran yang tidak mencukupi. Tidak ada data pasti mengenai fluktuatif harga yang diberikan oleh supplier dan juga pihak koperasi hanya mengacu ke beberapa supplier, padahal masih banyak supplier yang menawarkan harga lebih sesuai dan stok barang yang disediakannya pun dapat mencukupi kebutuhan dan juga pelaporan dari hasil pencatatan bulanan belum terekap secara keseluruhan karena terjadi perubahan anggaran belanja disetiap bulannya. Hal ini menyebabkan anggota koperasi melakukan pendataan ulang dari rekap bulanan untuk anggaran belanja selanjutnya serta informasi daftar harga dari setiap barang yang akan dibeli dan data supplier untuk memenuhi barang tersebut. Tujuan penelitian untuk menghasilkan informasi mengenai stok barang beserta jumlah pemesanan barang untuk periode selanjutnya sehingga dapat membuat rancangan anggaran yang sesuai.

Penelitian sebelumnya mengkaji bahwa metode supply chain management untuk meningkatkan efektivitas sistem distribusi produk sehingga mampu mengatasi jumlah permintaan yang di setarakan antara stok barang di gudang dengan distribusi barang dari supplier (Parwati, 2009). Penelitian lainnya mengemukakan supply chain management berbasis website pada pengoptimalan nilai suatu produk dan pengefisiensikan proses distribusi aliran produk tersebut dari hulu ke hilir (Ang, 2014). Penerapan supply chain management dengan informasi internet dapat menunjang dalam pengelolaan di berbagai bidang terutama stok ketersediaan barang, kolaborasi antara penggunaan teknologi peningkatan informasi terkait supply chain dan management supply chain di namakan e-scm (Purwanto, 1994).

Penelitian bertujuan untuk menghasilkan informasi mengenai stok barang beserta jumlah pemesanan barang untuk periode selanjutnya sehingga dapat membuat rancangan anggaran yang sesuai.

\section{Kerangka Teori}

\subsection{Supply Chain Management}

Supply chain management merupakan konsep baru dalam melihat persoalan logistic. Konsep lama melihat logistic lebih sebagai persoalan intern masingmasing perusahaan, dan pemecahannya dititikberatkan pada pemecahan secara intern di perusahaan masing-masing. Dalam konsep baru ini, masalah logistic dilihat sebagai masalah yang lebih luas yang terbentang sangat panjang sejak dari bahan dasar sampai barang jadi yang dipakai konsumen akhir, yang merupakan mata rantai penyediaan barang (Chopra, 2007). Terdapat banyak kegiatan umum disepanjang supply chain. Kegiatan umum ini memungkinkan untuk menghasilkan model dasar yang memungkinkan berbagai jenis supply chain untuk memuaskan tuntutan pasar yang unik dan memenangkannya. Pola aliran Supply Chain adalah pola yang terbentuk dari kegiatan bisnis dalam supply chain yaitu dimulai dari pengadaan bahan baku, pengolahan/ produksi, hingga pendistribusian produk ke costumer. Pola aliran supply chain yang terbentuk untuk setiap produk berbeda-beda tergantung dengan banyaknya pihak yang terlibat kegiatan yang bisnis dan tergantung jenis produk itu sendiri (Hugos, 2003).

\subsection{Fluktuasi Harga}

Perusahaan pada waktu tertentu mengadakan berbagai macam diskon, seperti: diskon harga, diskon jumlah, kupon atau special promosi untuk produkproduk tertentu. Customer akan membeli lebih banyak dari ukuran pesanan normal sehingga terjadi fluktuasi harga. Pengecer atau toko melakukan forward buying atau membeli lebih awal sebagai tanggapan terhadap penurunan harga yang bersifat sementara. Reaksi toko-toko dan pengecer ini sering kali mengakibatkan volulme penjualan meningkat bahkan tidak jarang melebihi prediksi pusat distribusi. Akibatnya pusat distribusi akan memesan dengan jumlah yang lebih besar ke pabrik. Pabrik merespon kebutuhan ini dengan meningkatkan aktivitas produksi, dapat 
dengan lembur atau memesan ke sub kontraktor. Pabrik tidak memliki cukup bahan baku untuk mengantisipasi kenaikan secara tiba-tiba ini dan mereka memesan tambahan ke supplier (Heizer, 2006).

\subsection{ABC Pareto}

Sistem klasifikasi ABC merupakan suatu prosedur sederhana yang didasarkan pada nilai rupiah pembelian. Klasifikasi ABC merupakan petunjuk bagi manajemen dalam memberikan prioritas pengawasan persediaan. Item kelompok A harus dilakukan dengan kelompok B maupun C. Pengklasifikasian berdasarkan konsep ABC Pareto dilakukan dengan mengelompokan berdasarkan nilai pemakaian (Hong, 2015).

\subsection{Perhitungan Economic Order Quantity (EOQ)}

Model sederhana yang bisa digunakan untuk menentukan ukuran pesanan ekonomis dan dibuat dengan sejumlah asumsi. Model ini hanya digunakan dengan cukup baik apabila sejumlah asumsi terpenuhi atau setidaknya mendekati. Asumsi pertama adalah permintaan terhadap suatu item bersifat terus menerus dengan tingkat seragam. Item tersebut dibutuhkan dengan jumlah yang sama dari waktu ke waktu. Dalam kenyataannnya asumsi ini tidak pernah terpenuhi. Namun demikian, model ini tetap cukup baik digunakan asalkan variasi permintaan dari waktu ke waktu tidak terlalu besar (Puspita, 2013).

Untuk menghitung EOQ dapat dilakukan dengan persamaan (1).

$$
Q=\sqrt{\frac{2 D S}{H}}
$$

Dimana Q: jumlah optimal barang per pesanan, D: kebutuhan tahunan barang persediaan dalam unit/tahun, S: biaya pemesanan untuk setiap tahun dan $\mathrm{H}$ : biaya penyimpanan per unit/tahun.

Penentuan waktu pemesanan kembali bahan baku perlu ditentukan. Hal ini dilakukan agar pembelian bahan yang sudah ditetapkan dalam perhitungan EOQ tidak mengganggu kelancaran kegiatan produksi. Faktor yang mempengaruhinya adalah waktu yang diperlukan dari saat pemesanan sampai bahan datang, tingkat pemakaian bahan rata-rata dalam satuan waktu tertentu, safety stock dan tingkat minimum.

\section{Metode}

\subsection{Metode Pengumpulan Data}

Metode pengumpulan data dilakukan dengan pengamatan di sebuah koperasi dan melakukan tanya jawab secara langsung kepada pihak yang mengetahui proses bisnis yang terjadi.

\subsection{Perancangan Pola Aliran Supply Chain} Management

Rancangan chain yang akan digunakan adalah chain 1-2-3-4: Supplier - Manufacturer Distributor/Wholesaler - Retail Outlets. Dasar penggunaan dari chain tersebut adalah karena objek yang diteliti adalah sebuah koperasi, maka chain yang digunakan sesuai dengan objek tersebut adalah 1-2-34: Supplier - Manufacturer - Distributor/Wholesaler - Retail Outlets.

\subsection{Strategi Mengelola Supply Chain Management}

Pengelolaan Supply Chain Management yang akan dibahas meliputi pengelolaan manajemen pengadaan dan manajemen persediaan stok barang

a. Perancangan Pengelompokan Analisis ABC Pareto

Klasifikasi barang yang data dari supplier sebelum masuk masuk ke dalam gudang penyimpanan, barang tersebut akan diklasifikasikan atau dikelompokan sesuai dengan nilai pemakaian dari masing-masing barang tersebut.

b. Perhitungan Economic Order Quantity (EOQ)

Pemodelan dari setiap barang yang sudah masuk kedalam gudang penyimpanan barang dan dibuatkan tabel dengan menggunakan persamaan EOQ untuk menentukan jumlah pemesanan ekonomis dari setiap pemesanan masing-masing barang.

c. Penentuan titik pembelian barang

Tahap penentuan titik pembelian barang atau Reorder Point (ROP) merupakan tahap yang memberikan informasi terhadap pihak koperasi agar selalu memantau persediaan dari masing-masing barang, dan jika barang tertentu sudah mencapai titik dimana harus melaku.kan pembelian, maka pihak koperasi harus melakukan pembelian tersebut sejumlah hasil perhitungan dari eoq sebelumnya.

\subsection{Alur Proses}

Alur proses dilakukan untuk memenuhi kebutuhan pengguna dan sistem yang dibangun, interaksi dengan sistem dimodelkan bersama dengan fungsi-fungsi yang diperlukan oleh sistem seperti melakukan pendataan barang masuk dan keluar dan juga manajemen perencanaan pembelian stok barang digudang untuk persediaan selanjutnya.

\subsection{Implementasi}

Implementasi stok gudang berbasis website dibangun untuk membantu dalam merencanakan dan mengelola stok gudang koperasi.

\subsection{Pengujian}

Pengujian menggunakan usability test dan dilakukan terhadap pengguna sistem pengelolaan stok gudang koperasi. 


\section{Hasil dan Pembahasan}

\subsection{Perancangan Pola Aliran Supply Chain Management}

Pola aliran supply chain management untuk koperasi terdiri dari supplier produk, koperasi dan customer. Pola aliran informasi supply chain management koperasi rimbawan dimulai dari pemesanan produk oleh pihak koperasi kepada supplier, informasi pemesanan diteruskan dengan pihak supplier melakukan pengecekan ketersediaan pesanan, jika pesanan tersedia maka akan langsung diproses pesanan tersebut tapi jika tidak tersedia maka supplier akan memberikan pesanan tersebut ke supplier lain. Untuk kebutuhan stok barang staff gudang membagi informasi kepada kepala koperasi, jika mendapati persediaan stok barang menipis dari bagian gudang, maka akan dilakukan perincian stok barang yang harus dibeli. Setelah pemesanan selesai dan barang sudah dikirimkan oleh supplier bagian gudang memasukan barang tersebut ke dalam gudang stok barang sambil melakukan pendataan jumlah barang yang masuk. Kemudian pihak gudang membuat laporan barang yang masuk ke dalam gudang dan sekretaris mendapat informasi mengenai biaya pengeluaran anggaran untuk pengadaan stok barang dan informasi mengenai jumlah stok barang yang ada.

Aliran finansial pada supply chain management koperasi terjadi pada customer, koperasi dan supplier. Sistem transaksi untuk customer dengan pembayaran tunai ketika hendak membeli suatu produk. Sistem transaksi antara koperasi dengan supplier dilakukan dengan pembayaran tunai yaitu pihak koperasi membayar langsung sesuai dengan pesanan yang diajukan kepada supplier. Aliran pengembalian terjadi ketika produk yang didapati oleh pihak koperasi tidak sesuai dengan pesanan. Aliran pengembalian produk yang dilakukan oleh customer terjadi apabila diharapkan oleh customer sesuai dengan jenis produk yang dibeli oleh masing-masing costumer.

\subsection{Strategi Mengelola Supply Chain Management} a. Manajemen Pengadaan

Manajemen pengadaan merupakan kegiatan mengelola penyedia stok barang atau bahan baku untuk keperluar proses bisnis. Ketersediaan stok barang merupakan hal pokok untuk kelangsungan proses penjualan. Untuk itu koperasi dituntut untuk melakukan kegiatan yang berhubungan dengan penadaan dengan baik. Berikut merupakan usulan kriteria yang dapat digunakan koperasi untuk proses pemilihan supplier baru, yaitu aspek finansial, kualitas, ketepatan waktu kirim dan komunikasi.

b. Manajemen Persediaan Stok Barang

1). Persediaan Stok Barang

Persediaan stok barang merupakan sesuatu yang vital untuk kelangsungan proses penjualan. Apabila terjadi kekosongan stok barang maka penjualan tidak dapat berjalan. Hal ini mengakibatkan kerugian bagi koperasi. Dalam hal ini dapat dilakukan perencanaan dan pengendalian stok barang, sehingga kelangsungan proses penjualan produk dapat berjalan dengan lancar. 2). Pengelompokan Analisis ABC Pareto

Analisis ABC Pareto membagi persediaan stok barang kedalam tiga kelas berdasarkan jumlah pemakaian dan nilai rupiah kuantitatifnya. Stok barang yang digunakan dalam proses penjualan sangat beragam. Umumnya persediaan terdiri dari berbagai jenis barang dengan jumlah yang banyak, dimana masing-masing jenis barang membutuhkan analisis sendiri untuk mengetahui besarnya order size dan order point. Berbagai jenis produk tersebut tidak seluruhnya memiiki tingkat prioritas yang sama. Oleh karena itu, untuk mengetahui jenis-jenis bahan baku yang perlu mendapat prioritas maka dapat menggunakan analisis ABC Pareto. Penentuan kelas ABC Pareto terhadap stok produk koperasi terlihat pada Tabel 1.

\begin{tabular}{|c|c|c|c|c|c|c|c|c|}
\hline $\begin{array}{l}\mathrm{N} \\
\mathrm{o}\end{array}$ & Item & $\begin{array}{l}\text { Pemak } \\
\text { aian }\end{array}$ & $\begin{array}{l}\text { Har } \\
\text { ga } \\
\text { per } \\
\text { unit } \\
\text { (rib } \\
\text { u) }\end{array}$ & $\begin{array}{l}\text { Tot } \\
\text { al } \\
\text { bia } \\
\text { ya } \\
\text { (rib } \\
\text { u) }\end{array}$ & $\begin{array}{l}\text { Volu } \\
\text { me } \\
\text { unit } \\
(\%)\end{array}$ & $\begin{array}{l}\text { Kumul } \\
\text { atif } \\
\text { unit } \\
(\%)\end{array}$ & $\begin{array}{l}\text { Total } \\
\text { kumul } \\
\text { atif } \\
\text { unit } \\
(\%)\end{array}$ & $\begin{array}{l}\text { Kel } \\
\text { as }\end{array}$ \\
\hline 1 & Beras & $\begin{array}{l}31 \\
\text { karung }\end{array}$ & 12,5 & $\begin{array}{l}3,8 \\
75\end{array}$ & 35,92 & 35,92 & & \\
\hline 2 & $\begin{array}{l}\text { Kemej } \\
\text { a }\end{array}$ & $15 \mathrm{pcs}$ & 60 & 900 & 8,34 & 44,26 & & \\
\hline 3 & Kaos & $22 \mathrm{pcs}$ & 40 & 880 & 8,15 & 52,41 & & \\
\hline 4 & $\begin{array}{l}\text { Kertas } \\
\text { A4 }\end{array}$ & $26 \mathrm{rim}$ & 33 & 858 & 7,95 & 60,36 & 71,18 & A \\
\hline 5 & $\begin{array}{l}\text { Minya } \\
\mathrm{k} \\
\text { goreng }\end{array}$ & $26 \mathrm{pcs}$ & 23 & 598 & 5,54 & 65,9 & & \\
\hline 6 & $\begin{array}{l}\text { Kertas } \\
\text { F4 }\end{array}$ & $19 \mathrm{rim}$ & 30 & 570 & 5,28 & 71,18 & & \\
\hline 7 & $\begin{array}{l}\text { Baso } \\
\text { olah }\end{array}$ & $27 \mathrm{pcs}$ & 18 & 486 & 4,50 & 75,68 & & \\
\hline 8 & $\begin{array}{l}\text { Binder } \\
\text { clip }\end{array}$ & $94 \mathrm{pcs}$ & 4 & 376 & 3,84 & 79,52 & & \\
\hline 9 & $\begin{array}{l}\text { Daimar } \\
\text { u }\end{array}$ & $47 \mathrm{pcs}$ & 7,5 & $\begin{array}{l}352 \\
.5\end{array}$ & 3,26 & 82,78 & & \\
\hline $\begin{array}{l}1 \\
0\end{array}$ & $\begin{array}{l}\text { Gula } \\
\text { pasir }\end{array}$ & $26 \mathrm{~kg}$ & 12,5 & $\begin{array}{l}325 \\
.5\end{array}$ & 3,01 & 85,74 & 20,41 & B \\
\hline $\begin{array}{l}1 \\
1\end{array}$ & $\begin{array}{l}\text { Air } \\
\text { mineral }\end{array}$ & 13 dus & 24,5 & $\begin{array}{l}318 \\
, 5\end{array}$ & 2,95 & 88,74 & & \\
\hline $\begin{array}{l}1 \\
2\end{array}$ & $\begin{array}{l}\text { Susu } \\
\text { murni }\end{array}$ & $44 \mathrm{pcs}$ & 7 & 308 & 2,85 & 91,59 & & \\
\hline $\begin{array}{l}1 \\
3\end{array}$ & $\begin{array}{l}\text { Tepung } \\
\text { terigu }\end{array}$ & $34 \mathrm{~kg}$ & 9 & 306 & 2,83 & 94,42 & & \\
\hline $\begin{array}{l}1 \\
4\end{array}$ & $\begin{array}{l}\text { Amplo } \\
\text { p }\end{array}$ & 18 dus & 13 & 234 & 2,16 & 96,58 & & \\
\hline $\begin{array}{l}1 \\
5\end{array}$ & $\begin{array}{l}\text { Handu } \\
\mathrm{k}\end{array}$ & $7 \mathrm{pcs}$ & 27 & 189 & 1,75 & 98,33 & 8,37 & C \\
\hline $\begin{array}{l}1 \\
6\end{array}$ & $\begin{array}{l}\text { Otak- } \\
\text { otak }\end{array}$ & $17 \mathrm{pcs}$ & 7 & 119 & 1,1 & 99,43 & & \\
\hline $\begin{array}{l}1 \\
7 \\
\end{array}$ & $\begin{array}{l}\text { Blockn } \\
\text { ote }\end{array}$ & $23 \mathrm{pcs}$ & 2,5 & $\begin{array}{l}57, \\
5\end{array}$ & 0,53 & 99,96 & & \\
\hline
\end{tabular}

Pada Tabel 1, pembagian kelas menyatakan bahwa sebuah group selalu memiliki persentase terkecil yang bernilai atau memiliki dampak terbesar. Pada model analisis $\mathrm{ABC}$ Pareto jumlah produk yang terdapat pada tabel 1 dikelompokan ke dalam 3 kelompok besar yaitu kelompok A (sangat penting), B (penting), dan $C$ (kurang penting). Setiap kelompok memiliki porsi penyerapan modal dan jumlah produk yang berbeda-beda. Untuk menghitung penggunaan biaya jenis persediaan tertentu, basis yang digunakan adalah 
jumlah unit kebutuhan persediaan per periode dikalikan dengan biaya per unit. Kategori A adalah persediaan yang berjumlah sekitar $15-20 \%$ dari jumlah total persediaan tetapi menghabiskan sekitar $70 \%$ dari total biaya persediaan dalam setahun. Kategori B adalah persediaan dengan jumlah sekitar 20-35\% dari jumlah total persediaan, tetapi menghabiskan dana sekitar $20 \%$ dari total biaya persediaan. Kategori $\mathrm{C}$ adalah persediaan dengan jumlah sekitar $50 \%$ dari total persediaan dan hanya menghabiskan dana sekitar $10 \%$ saja dari total biaya persediaan per periode.

Untuk menghitung \% Volume unit, \% Kumulatif unit, dan $\%$ Total kumulatif unit adalah sebagai berikut:

1. \% Volume unit $=$ Pemakaian $x$ harga per unit

2. $\%$ Kumulatif unit $=$ Total biaya keseluruhan / total biaya per unit x $100 \%$

3. $\%$ Total kumulatif unit $=$ Jumlah dari $\%$ volume unit (Penjumlahan satu kelas)

Berdasarkan Tabel 1, dapat dilihat bahwa produk yang termasuk dalam kelompok A adalah Beras, Baju, Kertas dan Minyak goring. Kelompok A memiliki persentase kumulatif jumlah produk sebesar $71,18 \%$ atau sebanyak 6 item produk. Selain itu, kelompok A memiliki menggunakan penyerapan modal sebesar Rp. 7.111.000 dari jumlah total biaya persediaan stok produk sejumlah Rp. 10.786.500.

Produk yang termasuk ke dalam kelompok B adalah Baso olah, Binder clip, Daimaru lakban, Gula pasir, Air mineral, dan Susu murni. Kelompok B memiliki persentase kumulatif produk sebanyak $20,41 \%$ atau sebanyak 6 item. Selain itu, kelompok B menggunakan penyerapan modal sebesar Rp. 1.540.000 dari jumlah total biaya persediaan bahan baku sejumlah Rp. 10.786.500.

Produk yang termasuk ke dalam kelompok C adalah Tepung terigu, Amplop, Handuk, Otak-otak, dan Block note. Kelompok C memiliki persentase kumulatif produk sebanyak $8,37 \%$ atau sebanyak 5 item. Selain itu, kelompok C menggunakan penyerapan modal sebesar Rp. 905.500 dari jumlah total biaya persediaan bahan baku sejumlah $\mathrm{Rp}$. 10.786.500.

Dari klasifikasi bahan baku ini pihak koperasi dapat membuat kebijakan sebagai berikut:

a. Pengembangan sumber dana untuk persediaan produk kategori A yang harus lebih di tingkatkan.

b. Untuk produk kategori A dibutuhkan pengendalian yang lebih ketat disbanding dengan produk kategori B dan C.

c. Perkiraan pengadaan stok produk untuk kategori A harus lebih hati-hati disbanding dengan produk kategori B dan C.

Berdasarkan hasil analisis $\mathrm{ABC}$ Pareto, pihak koperasi harus mengendalikan persediaan produk yang lebih ketat terhadap produk yang termasuk kelompok A, karena kelompok A memiliki jumlah pemakaian yang lebih banyak dibanding dengan kelompok B dan C. Selain itu ada kelompok A memiliki penyerapan modal persediaan bahan baku yang lebih besar dibanding kelompok B dan C. Oleh karena itu, pihak koperasi harus melakukan analisis ABC Pareto terhadap stok produk secara periodic terutama jika terjadi perubahan volume produksi, penambahan jenis persediaan, sehingga menajemen atau pengendalian persediaan tetap terkontrol dengan baik. Daftar stok produk dalam kelas-kelas klasifikasi ABC Pareto bisa berubah, misal salah satu produk yang tadinya berada di kelas A bisa pindah ke kelas B atau C. Perubahan bisa terjadi berdasarkan kebutuhan pemakaian serta periode waktu perencanaan.

\section{3). Perhitungan Economic Order Quantity (EOQ)}

Koperasi menyusun anggaran stok barang untuk periode Juni-September 2016. Anggaran yang disusun berdasarkan data tahun 2015. Dari periode tersebut penggunaan produk sebanyak 489 item dari 17 macam produk. Sesuai hasil observasi data-data pendukung untuk perhitungan EOQ seperti data penyimpanan bahan baku tidak ada sehingga digunakan untuk biaya penyimpanan sebesar $12 \%$ dari unit cost tiap produk (Heizer, 2006). Sedangkan data pemesanan bahan baku berdasarkan hasil observasi didapatkan sebesar rata-rata $\mathrm{Rp} 10.000$ untuk setiap produk selama 3 bulan. Berikut perincian pemakaian produk yang akan dijelaskan pada Tabel 2 .

\begin{tabular}{|c|c|c|c|c|c|c|c|}
\hline No & Item & $\begin{array}{l}\text { Pemakaian } \\
\text { unit per } 3 \\
\text { bulan }\end{array}$ & $\begin{array}{l}\text { Biaya } \\
\text { pemesan } \\
\text { an (ribu) }\end{array}$ & $\begin{array}{l}\text { Total } \\
\text { biaya } \\
\text { (ribu) }\end{array}$ & Lead & $\begin{array}{l}\text { Pemakaian per } \\
\text { hari }\end{array}$ & $\begin{array}{l}\text { Safety } \\
\text { Stock }\end{array}$ \\
\hline 1 & Beras & 31 karung & 10 & 1,5 & 2 & 0,34 & 20 \\
\hline 2 & Kemeja & $15 \mathrm{pcs}$ & 10 & 7,2 & 2 & 0,16 & 6 \\
\hline 3 & Kaos & $22 \mathrm{pcs}$ & 10 & 4,8 & 2 & 0,24 & 9 \\
\hline 4 & Kertas A4 & $26 \mathrm{rim}$ & 10 & 3,96 & 2 & 0,28 & 12 \\
\hline 5 & $\begin{array}{l}\text { Minyak } \\
\text { goreng }\end{array}$ & $26 \mathrm{pcs}$ & 10 & 2,76 & 2 & 0,28 & 14 \\
\hline 6 & Kertas F4 & $19 \mathrm{rim}$ & 10 & 3,6 & 2 & 0,21 & 10 \\
\hline 7 & Baso olah & $27 \mathrm{pcs}$ & 10 & 2,16 & 2 & 0,13 & 16 \\
\hline 8 & Binder clip & $94 \mathrm{pcs}$ & 10 & 0,48 & 2 & 1 & 62 \\
\hline 9 & Daimaru & $47 \mathrm{pcs}$ & 10 & 0,900 & 2 & 0,52 & 32 \\
\hline 10 & Gula pasir & $26 \mathrm{~kg}$ & 10 & 1,5 & 2 & 0,28 & 19 \\
\hline 11 & Air mineral & 13 dus & 10 & 2,94 & 2 & 0,21 & 9 \\
\hline 12 & Susu murni & $44 \mathrm{pcs}$ & 10 & 0,840 & 1 & 0,48 & 32 \\
\hline 13 & $\begin{array}{l}\text { Tepung } \\
\text { terigu }\end{array}$ & $34 \mathrm{~kg}$ & 10 & 1,080 & 2 & 0,37 & 25 \\
\hline 14 & Amplop & 18 dus & 10 & 1,560 & 2 & 0,2 & 15 \\
\hline 15 & Handuk & $7 \mathrm{pcs}$ & 10 & 3,240 & 2 & 0,07 & 6 \\
\hline 16 & Otak-otak & $17 \mathrm{pcs}$ & 10 & 0,840 & 1 & 0,18 & 20 \\
\hline 17 & Blocknote & $23 \mathrm{pcs}$ & 10 & 0,300 & 2 & 0,25 & 39 \\
\hline
\end{tabular}

Perhitungan kuantitas paling ekonomis untuk pemesanan produk beras dan produk lainnya (2):

$$
\begin{aligned}
Q=\sqrt{2} & D S / H \\
Q(\text { Beras }) & =\frac{\sqrt{2 \times 31 \times 10000}}{1500} \\
& =\sqrt{413.33} \\
& =20.33
\end{aligned}
$$

Jadi, frekuensi pembelian dalam 3 bulan adalah

$$
\begin{aligned}
\frac{31 \mathrm{karung}}{20 \mathrm{karung}} & =1.5 \mathrm{kali} \\
& =1 \mathrm{kali}
\end{aligned}
$$




\section{4). Perhitungan titik pembelian barang}

Penentuan titik pembelian barang atau Reorder Point (ROP). Untuk penentuan waktu pemesanan kembali produk (Reorder Point), rata-rata lead time produk adalah 2 hari, tingkat pemakaian per hari untuk beras adalah 0.34 dan safety stock beras adalah 20 karung, maka:

$$
\begin{aligned}
& R O P=(2 x 0.34)+2 \\
& R O P=2.68=3 \text { karung }
\end{aligned}
$$

Jadi, apabila beras sudah mencapai titik 3 karung maka pihak koperasi harus melakukan pemesanan kembali.

Pada Tabel 3 perhitungan EOQ dan ROP untuk semua produk. Dengan adanya proses pencatatan yang baik, melakukan pengelompokan produk dengan analisis ABC Pareto dan melakukan perhitungan EOQ dan ROP, koperasi dapat mengendalikan persediaan stok barang sehingga meminimalisir terjadinya kekosongan stok barang. Pihak koperasi dapat mengetahui berapa kuantitas ekonomis pemesanan produk dan waktu kapan dilakukan pemesanan kembali. Hal ini mempermudah pihak koperasi untuk berkoordinasi dengan supplier mengenai kebutuhan produk, supplier juga dapat merencanakan stok barang setelah mendapat informasi pesanan dari pihak koperasi. Kegiatan tersebut diharapkan dapat mengatasi kekosongan produk yang terjadi pada stok barang di gudang.

\section{Tabel 3. Perhitungan EOQ dan ROP}

\begin{tabular}{cllll}
\multicolumn{5}{l}{ Tabel } \\
\hline No & Item & EOQ & Frekuensi & ROP \\
\hline 1 & Beras & 20 & 1 & 3 \\
2 & Kemeja & 6 & 2 & 3 \\
3 & Kaos & 9 & 2 & 2 \\
4 & Kertas A4 & 12 & 2 & 2 \\
5 & Minyak goreng & 14 & 2 & 2 \\
6 & Kertas F4 & 10 & 2 & 2 \\
7 & Baso olah & 16 & 2 & 3 \\
8 & Binder clip & 62 & 1 & 4 \\
9 & Daimaru & 32 & 1 & 3 \\
10 & Gula pasir & 19 & 1 & 2 \\
11 & Air mineral & 9 & 1 & 2 \\
12 & Susu murni & 32 & 1 & 2 \\
13 & Tepung terigu & 25 & 1 & 3 \\
14 & Amplop & 15 & 1 & 2 \\
15 & Handuk & 6 & 1 & 2 \\
16 & Otak-otak & 20 & 1 & 1 \\
17 & Blocknote & 39 & & 2 \\
\hline & & & 1 & \\
\hline
\end{tabular}

\subsection{Alur proses}

Gambaran mengenai sistem yang dibuat maka digunakan proses dan data model dari sistem yang akan dimodelkan dengan diagram use case. Pengguna terdiri dari Admin, Kepala Koperasi, Staf Gudang dan Sekretaris. Alur terdapat pada Gambar 1.

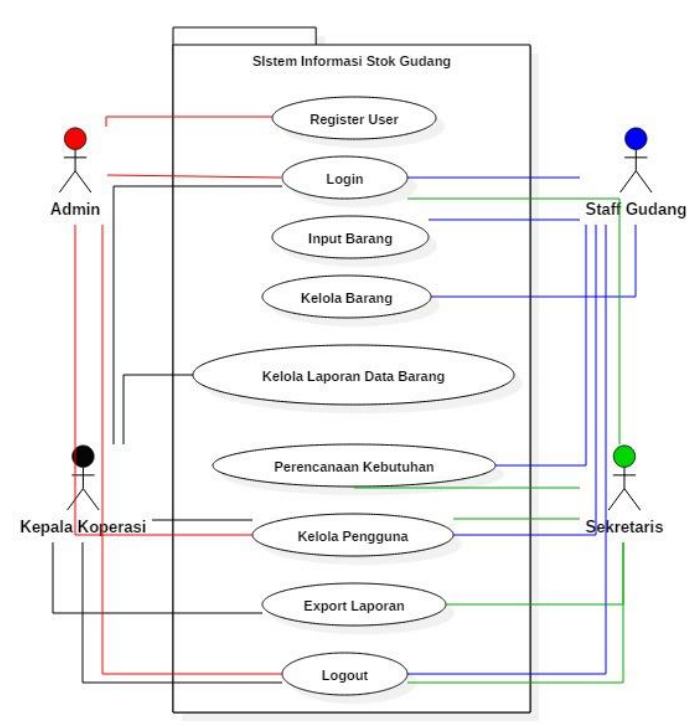

Gambar 1. Alur proses sistem informasi stok barang

\subsection{Implementasi}

Terdapat 5 tampilan implementasi stok gudang berbasis website untuk membantu dalam merencanakan dan mengelola stok gudang koperasi, yaitu: Barang masuk, merealisasikan anggaran, menambah pemasukan, laporan laba rugi dan harga jual produk.

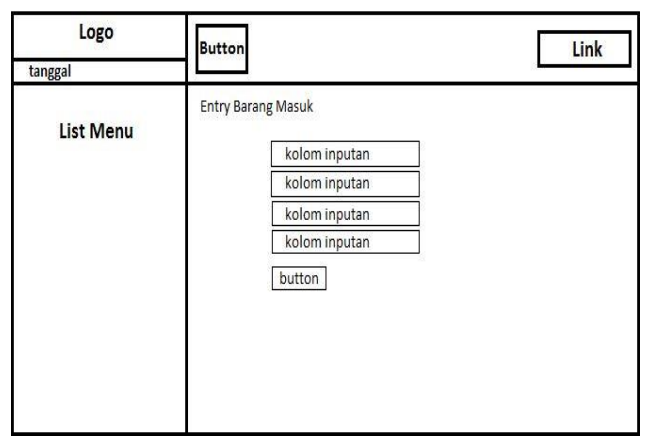

Gambar 2. Barang masuk

Pada Gambar 2 data barang dimasukan ke dalam menu data barang kemudian data tersebut di lengkapi dengan menambahkan tanggal masuk dan jumlah kuantitas dari masing-masing barang, karena pada proses ini data awal yang di masukan akan di catat masuk ke dalam gudang penyimpanan.

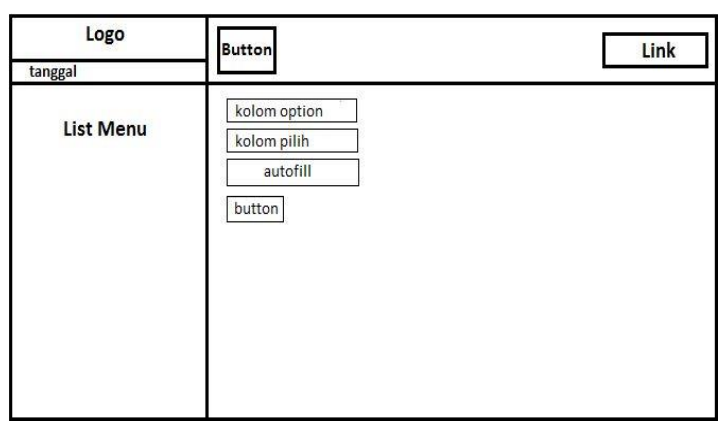

Gambar 3. Perencanaan kebutuhan 
Pada Gambar 3 digunakan oleh staff gudang dalam merencanakan kebutuhan perbelanjaan dari masingmasing barang, dan juga menentukan jumlah yang harus dibeli dari barang tersebut agar tidak terjadi kekurangan maupun kelebihan stok barang di gudang.

\begin{tabular}{|c|c|c|c|}
\hline Logo & \multirow{2}{*}{ Button } & & \multirow[t]{2}{*}{ Link } \\
\hline tanggal & & & \\
\hline \multirow{10}{*}{ List Menu } & autofill & \multirow{10}{*}{$\begin{array}{l}\text { Hasil kalkulasi } \\
\text { perencanaan } \\
\text { kebutuhan }\end{array}$} & \\
\hline & autofill & & \\
\hline & autofill & & \\
\hline & \begin{tabular}{|l|l|l|l} 
autofill \\
\end{tabular} & & \\
\hline & kolom input & & \\
\hline & $\begin{array}{ll}\text { kolom input } \\
\end{array}$ & & \\
\hline & \begin{tabular}{|l|} 
kolom input \\
\end{tabular} & & \\
\hline & \begin{tabular}{|l|} 
autofill \\
\end{tabular} & & \\
\hline & \begin{tabular}{|l|} 
autofill \\
\end{tabular} & & \\
\hline & button & & \\
\hline
\end{tabular}

Gambar 4. Kalkulasi dan perhitungan EOQ

Pada Gambar 4 merupakan kelanjutan dari hasil input data perencanaan. Setelah menginput data barang yang akan ditentukan berapa jumlah pembelian untuk selanjutnya maka diteruskan menuju halaman kalkulator eoq yang akan menampilkan hasil perhitungan untuk jumlah ekonomis pembelian barang selanjutnya.

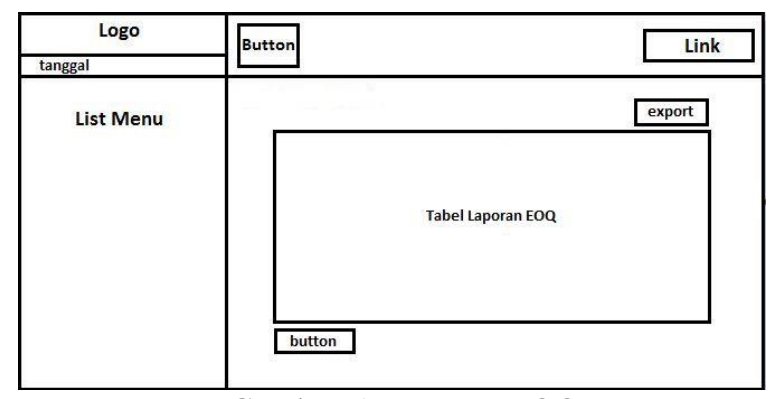

Gambar 5. Laporan EOQ

Pada Gambar 5 berfungsi untuk merekap data laporan hasil perencanaan yang dilakukan oleh staff gudang. Kepala koperasi dapat mengetahui dengan detail hasil kalkulasi dari perencanaan masing-masing barangnya sehingga dapat menentukan kualitas dari masing-masing barang yang ada di gudang.

\subsection{Pengujian}

Pengujian menggunakan usability test. Pengujian dilakukan terhadap pengguna sistem pengelolaan stok gudang, hasil pengujian usability test diketahui bahwa prosentasi pertanyaan learnability mampu di jawab oleh responden sebesar $100 \%$, efficiency mampu dijawab sebesar 58.33\%, memorability mampu dijawab sebesar $66.66 \%$ dan eror sebanyak $8.33 \%$ mampu di jawab oleh responden, dari keseluruhan prosentase jawaban diakumulasikan dan didapatkan hasil sebesar $66.66 \%$ yang menyatakan bahwa sistem informasi stok gudang dinyatakan baik sehingga sistem layak dan dapat digunakan untuk proses penyimpanan data barang, perhitungan perencanaan barang, dan menampilkan laporan data barang.

\section{Kesimpulan}

Koperasi mengelompokan barang menjadi 3 kelompok, yaitu kelompok A adalah Beras, Baju, Kertas dan Minyak goreng. Kelompok A memiliki persentase kumulatif jumlah produk sebesar 71,18\% atau sebanyak 6 item produk. Kelompok B adalah Baso olah, Binder clip, Daimaru lakban, Gula pasir, Air mineral, dan Susu murni. Kelompok B memiliki persentase kumulatif produk sebanyak $20,41 \%$ atau sebanyak 6 item. Kelompok $\mathrm{C}$ adalah Tepung terigu, Amplop, Handuk, Otak-otak, dan Block note. Kelompok $\mathrm{C}$ memiliki persentase kumulatif produk sebanyak $8,37 \%$ atau sebanyak 5 item. Untuk penentuan waktu pemesanan kembali produk (Reorder Point), rata-rata lead time produk adalah 2 hari, tingkat pemakaian per hari untuk beras adalah 0.34 dan safety stock beras adalah 20 karung. Jadi, apabila beras sudah mencapai titik 3 karung maka pihak koperasi harus melakukan pemesanan kembali.

Sistem informasi stok gudang dapat membantu pihak koperasi dalam melakukan pendataan barang agar lebih mudah dalam pemesanan barang di periode selanjutnya, informasi yang tepat mengenai sisa stok barang di gudang dan juga perhitungan eoq yang berguna untuk mengurangi dampak kekurangan maupun kelebihan stok barang di gudang.

Berdasarkan hasil pengujian usability test diketahui bahwa prosentasi pertanyaan learnability mampu di jawab oleh responden sebesar 100\%, efficiency mampu dijawab sebesar 58.33\%, memorability mampu dijawab sebesar $66.66 \%$ dan eror sebanyak $8.33 \%$ mampu di jawab oleh responden, dari keseluruhan prosentase jawaban diakumulasikan dan didapatkan hasil sebesar $66.66 \%$ yang menyatakan bahwa sistem informasi stok gudang dinyatakan baik.

Sistem ini dapat digunakan untuk menginput data, menampilkan sisa stok barang, menghitung kalkukasi perbelanjaan dari masing-masing barang untuk periode selanjutnya dan rekap laporan secara berkala.

\section{Daftar Pustaka}

Ang, H., 2014. Model Supply Chain Management dan Perancangan Aplikasi E-SCM Pada PT Indofood Sukses Makmur Tbk Bogasari Flour Mills Division. The Winners, 15(1), 72-84.

Chopra, S., Meindl, P., 2007. Supply Chain Management. M. Pfaltzgraff, Ed, Third Edi, Upper Saddle River, New Jersey: Perason Education, Inc. Heizer, J., Render, B., 2006. Operations Management. M. Pfaltzgraff, Ed, Eight Edi, Upper Saddle River, New Jersey: Perason Education, Inc. 
Hong, X., Indriyani, R., 2015. Analisis inventory management pada PT Sarana Lubritama Semesta. Agora 3(1), 470-476.

Hugos, M. 2003., Essentials of Supply Chain Management. Hoboken, New Jersey: John Wiley \& Sons, Inc.

Indrajit, R.E., Djokopranoto, R., 2002. Konsep Manajemen Supply Chain. Grasindo. Jakarta.

Parwati, I., Andrianto, P. 2009., Metode supply chain management untuk menganalisis bullwhip effect guna meningkatkan efektivitas sistem distribusi produk. Jurnal Teknologi, 2(1), 47-52.

Permadi, R.W., Mahendra, Y.A.S., 2014. Evaluasi pencatatan sistem pergudangan pada koperasi hikmah Pacitan. Speed- Sentra Penelitian Engineering dan Edukasi, 6(4), 59-63.
Purwanto, H., Alfiani, D., 1994. Perancangan Sistem Informasi Pengendalian persediaan barang dengan pendekatan supply chain management pada PT. Kereta Api Balai Yasa. Sintelis, 1, 31-32.

Puspika, J., Anita, D., 2013. Inventory control dan perencanaan persediaan bahan baku produksi roti pada pabrik roti bobo Pekanbaru. Jurnal Ekonomi, 21(September), 1-15.

Saputro, P., Aryadita, H., Priyambadha, B., 2017. Pengembangan sistem informasi electronic supply chain management (studi kasus: CV. Baiducha Technology). Jurnal Pengembangan Teknologi Informasi dan Ilmu Komputer, vol. 2, no. 4, p. 1382-1389. 